\title{
Decision Support for International Agreements Regulating Nanomaterials
}

\author{
Ineke Malsch (D) - Martin Mullins • Elena Semenzin • \\ Alex Zabeo • Danail Hristozov • Antonio Marcomini
}

Received: 4 July 2017 / Accepted: 5 February 2018 / Published online: 27 February 2018

(C) Springer Science+Business Media B.V., part of Springer Nature 2018

\begin{abstract}
Nanomaterials are handled in global value chains for many different products, albeit not always recognisable as nanoproducts. The global market for nanomaterials faces an uncertain future, as the international dialogue on regulating nanomaterials is still ongoing and risk assessment data are being collected. At the same time, regulators and civil society organisations complain about a lack of transparency about the presence of nanomaterials on the market. In the project on
\end{abstract}

I. Malsch $(\bowtie)$

Malsch TechnoValuation, PO Box 455, 3500 AL Utrecht,

The Netherlands

e-mail: postbus@malsch.demon.nl

M. Mullins

Department of Accounting and Finance, Kemmy Business School, University of Limerick, Limerick, Ireland

e-mail: Martin.Mullins@ul.ie

E. Semenzin · A. Zabeo • D. Hristozov • A. Marcomini

Department of Environmental Sciences, Informatics and Statistics, Ca' Foscari University of Venice, via Torino 155 ,

30172 Mestre-Venezia, Italy

\section{E. Semenzin}

e-mail: semenzin@unive.it

A. Zabeo

e-mail: alex.zabeo@unive.it

D. Hristozov

e-mail: danail.hristozov@unive.it

A. Marcomini

e-mail: marcom@unive.it
Sustainable Nanotechnologies (SUN, www.sun-fp7.eu), a Decision Support System (SUNDS) has been developed, primarily for confidential use by risk and sustainability managers inside a company or consortium. In this article, we formulate a scenario concerning a potential role for an open access decision support system in negotiations on international agreements regulating trade in nanomaterials. The scenario includes design rules for decision support systems as well as procedures for use of such a system in stakeholder dialogue and policy-making on governance of these and other emerging technologies. This article incorporates analysis of results of stakeholder engagement on nanomaterials as well as literature and internet sources suggested by these stakeholders.

Keywords Nanomaterials · Decision support · Sustainable development $\cdot$ Nanosafety $\cdot$ Global governance

\section{Introduction}

Nanomaterials were first intentionally manufactured and introduced on the market over two decades ago, even though unintentionally fabricated nanomaterials have been incorporated in products for centuries. Often quoted examples include mediaeval stained-glass windows with gold (red) and silver (yellow) nanoparticles. Inspired by evidence of health and environmental hazards of ultrafine aerosols, critical NGOs raised the alarm in 2003 about the introduction to market of sun screens 
incorporating $\mathrm{TiO} 2$ and $\mathrm{ZnO}$ nanoparticles without additional safety testing. Governments and the European Commission responded by substantial investments in broad-ranging research in and dialogue on ethical, legal and social aspects of nanotechnologies, as well as in environment, health and safety analysis of nanomaterials. Over a decade later, the problem has been narrowed down to some concrete, as yet unresolved, issues. One issue is the lack of a centralised overview of nanosafety data allowing evidence-based risk governance and regulation of nanomaterials. The Sustainable Nanotechnologies Decision Support System (SUNDS) was designed to allow users to integrate all data available to them, together with an estimate of uncertainty in one dashboard. Once a database of all available nanosafety data is available, this can be imported into in the tool. Currently, a database on risk management measures (RMM) is included in SUNDS. Besides traditional risk assessment and risk management information, the system also asks for the inclusion of sustainability data supporting safer-by-design nanoenabled products (this includes life cycle assessment, social and economic impact assessments).

Another problem for policy-makers is the lack of international agreement on what would constitute an appropriate precautionary approach to the governance of risks of these nanomaterials. International dialogue on such governance has been ongoing, though mostly not visible to the average citizen. This article explores an integrated approach to more evidence-based as well as more democratic international governance of nanomaterials and other emerging technologies causing uncertainty and risk.

\section{Explaining the Sustainable Nanotechnologies Decision Support System}

A decision support system (DSS) is a system providing both problem-solving and communications capabilities for semi-structured problems [1]. DSS are often used in companies or organisations to support the management in decision-making, both for individual and group use. Recent examples are medical expert systems such as a tool for patient drug prescription [2], or tools for evaluating occupational risks, e.g. in shipyards [3]. Public authorities can also use them to verify compliance with existing regulations, e.g. to identify genetically modified food [4].
More recently, potential application of DSS tools using multi-criteria decision analysis (MCDA) is explored in supporting political decision-making, for example in conservation policy [5]. Specifically, MCDA tools have been proposed for use in sustainable energy policy development $[6,7]$. The SUNDS tool is an example of such an MCDA tool. This is a software integrating a set of criteria relevant to a decision-maker in one overview. In the case of SUNDS, these criteria are explained in the description of its modular design, further down in the text. For each of these criteria, a theoretical model is designed into the system, or accessed via a link to an external online module, calculating how input variables influence output indicators. These models vary from simple decision trees to complex (eco) toxicity, exposure and life cycle assessment models. The SUNDS system also requires the user to insert estimates of uncertainty, making visible not only the estimated value, but also what risk assessment studies would be needed to reduce uncertainty. In the current form of the SUNDS, the different criteria all have the same weight, because an earlier study of the LICARA nanoscan suggests that introducing weights does not have significant impact on the output of the system [8].

We developed the SUNDS ${ }^{1}$ DSS in the project on Sustainable Nanotechnologies (SUN). This project was funded by the European Union (EU) from 2013 until 2017. It aimed to protect innovation in sectors using nanomaterials, by providing industries with data and tools to streamline effective decision-making about safer nano-enabled products and manufacturing processes.

The design of SUNDS has been described by Subramanian et al. [9]. It consists of two tiers and uses MCDA to integrate technical data and user preferences in assessing risks from nano-enabled products and in comparing them to their benefits as part of socioeconomic analysis. If risks are present, the DSS provides options to reduce them as well as information on the associated costs.

Tier 1 is the nanoscan tool, first developed in the EUfunded project LICARA, ${ }^{2}$ and incorporated in SUNDS to address the needs of small and medium enterprises (SMEs), which often do not have the knowledge and the technical expertise to apply complex models. Therefore, nanoscan is a screening level semi-quantitative selfassessment tool that requires minimum data to evaluate

\footnotetext{
$\overline{{ }^{1} \mathrm{http}: / / \text { sunds.dais.unive.it }}$

$2 \mathrm{http} / / /$ cordis.europa.eu/project/rcn/105226_en.html
} 
the environmental, social and economic benefits and the ecological, occupational and consumer health risks of nano-enabled products to compare those to similar conventional products $[8,10]$.

Tier 2 is a more data-intensive system intended mostly for users from industry and regulatory agencies. It consists of risk control and socio-economic assessment modules, plus a stand-alone self-assessment tool to check compliance of the company's risk management procedures with the CENARIOS ${ }^{\mathrm{TM}}$ standard $[11,12]$. The risk control module performs both environmental and human health (occupational, consumer and public) risk assessment and helps the user select relevant RMM or technological alternatives to reduce the risk. The additional socio-economic assessment module performs life cycle impact assessment, economic assessment, and social impact assessment $[13,14]$. The results from applying the two modules can be plotted on charts that visualise the risk-benefit balance of the investigated nano-enabled products.

The risk assessment procedures implemented in tier 2 are in accordance with REACH guidelines (Regulation (EC) No 1907/2006 of the European Parliament and of the Council on the Registration, Evaluation, Authorisation and Restriction of Chemicals). ${ }^{3}$ From distributions of exposure and hazard, it is possible to derive probabilistic risks. This forms the basis for selecting appropriate RMM to control any unacceptable human health or ecological risks.

The current design of the SUNDS, DSS, targets industrial users wishing to assess the probable risks for human health and the environment, and to explore potential sustainability impacts of a nano-enabled product along its life cycle, assuming that varying risk control measures are adopted.

\section{Novelty of this Paper}

What is new in this paper compared with published work? This paper analyses suggestions made at a workshop in Edinburgh on 6 October 2016, which have not been discussed in earlier publications. There are similarities with a series of three papers analysing results of surveys, interviews and another user workshop from a mental modelling perspective [15-17]. The focus of those papers was on industrial and regulatory user

\footnotetext{
$\overline{3 \text { https://echa.europa.eu/regulations/reach }}$
}

contexts of the SUNDS tool while this was still in development. The present article explores the potential secondary uses of the finished tool, and possible requirements for redesigning the tool to make it more useful for supporting international governance of nanomaterials. It builds upon another earlier paper [18], which contained a proposal for wiki-like decision support in a global context, focusing mainly on philosophical and international relations theories. The present article takes the open questions left at the end of that paper as starting point, to include a more detailed analysis where such a decision support tool could be used and what the boundaries could be to its usefulness.

These questions are as follows:

1. How can citizens be empowered in international governance of nanomaterials through decision support?

2. What would be the optimal democratic and technically feasible option to ensure good data quality and the protection of proprietary data while allowing anyone to toggle with the weights?

3. Is it possible to allow users to insert their own weights and compare them with the average of their own peer group and other stakeholders?

4. Could the design be flexible enough to accommodate different emerging legislative frameworks? [18]

In the present article, we summarise these four questions into one: What would constitute an appropriate combination of a decision support tool based on SUNDS with democratic stakeholder engagement?

\section{Methodology}

In the following, we use a scenario development methodology, with input from stakeholders as well as constant comparison of the input with the state of research. This is in accordance with the SUN project-related objective to improve the system and examine possible applications. The primary data set consists of the report of a workshop held on 6 October 2016 in Edinburgh, which has not been analysed before in a publication. The summary report is included in annex 1 . Information sources mentioned by the participants were added to the data set. These are included in the references list. For comparison, participation notes in other relevant events 
by the authors are also added to the data set, to generate a more comprehensive overview of the studied field.

The stakeholder engagement reveals two distinct core themes in the discussion, around which interdisciplinary cooperation on two interconnected, innovative, boundary-spanning models aggregate. The first is the suggestion that an open access decision support model, expanding the current modular SUNDS tool should be constructed. This brings together knowledge from risk assessment and management with quantifiable life cycle assessment and corporate social responsibility/ socio-economic assessments. The sub-models and data originate from academics as well as industrial experts.

The second relates to a policy cycle for international governance of nanomaterials and other emerging technologies. This brings together insights from social sciences and humanities interested in regulation and governance of emerging technologies in a societal context, but also from professional policy makers and stakeholder representatives.

\section{Exploring Stakeholder Suggestions}

Three types of suggestions, made by participants in the stakeholder workshop, are explored below, to examine their relevance to fostering the use of decision support for international agreements governing nanomaterials. These include incremental as well as radical adaptations to the tool. The incremental adaptations fit in the same user scenario as the original SUNDS tool, for industrial decision-makers developing nano-enabled products. The radical adaptations envision another scenario where the tool is used for supporting policy making on international governance of nanomaterials and other emerging technologies. The proposals for more democratic decision-making and suggested connections between the two also fit in this international governance scenario.

Incremental Adaptation 1: Expanding the Decision Support System with a Business Ethics Module

Two related suggestions for expanding the SUNDS with a business ethics module were as follows:

\section{An Additional Module Could be Envisaged that} Includes a Taxonomy of Regulatory Regimes This could be useful for supporting joint regulatory risk assessment, for example
- high and low cost legal systems,

- open and closed legal systems and

- strict and low liability system.

A Business Ethics Tool Could be Useful It could incorporate a function warning if you are breaking current regulations in any country. Regulatory geography along the supply chain of a product could also be included to warn for non-tariff trade barriers.

Adding a business ethics module including a taxonomy of legal regimes, and a warning function if the value chain of the proposed product breaks current regulations in any country, could be useful for multinational companies, or for companies, which are active in international value chains. It could also generate useful information to insurance companies deciding whether to offer a policy covering the manufacturing of and trade in the product. Such a module would broaden the scope of risk assessment from toxicology and environmental impacts of the product to risks for the enterprise of national differences in legal frameworks in the countries where their suppliers or users are active. It is more comparable to the present CENARIOS ${ }^{\mathrm{TM}}$ self-assessment module for the risk management system at company level, than with the current risk control and socio-economic assessment modules, which all take the proposed new product as the cause of the assessed impacts.

Incremental Adaptation 2: Discussion of How Decision Support Systems can be Used for Risk Governance

A risk governance DSS for nanotechnologies would link different tools for (1) screening of apparent and perceived (phantom) risks; (2) qualitative and quantitative risk screening and assessment; (3) safety-by-design; and(4) risk surveillance, management and communication. Such a system would support the analysis and management of both emerging and existing nanomaterials and nano-enabled products at the innovation and post-product-launch stages. It would specifically support safety in innovation by aligning suitable assessment and decision support methods according to the Cooper Stage-Gate ${ }^{\circledR}$ innovation model. ${ }^{4}$ Its primary goal would be to enable (i) systematic risk analysis with clear understanding of data gaps and uncertainties, (ii) rational selection of suitable safer-by-design options and measures to reduce both risks and uncertainties, and

\footnotetext{
${ }^{4}$ http://www.stage-gate.com/resources_stage-gate.php
} 
(iii) third-party risk transfer (e.g. to the insurance industry). The system should be designed to establish high reliability and quality of risk assessment and management to increase the trust and confidence in all steps of the industrial and regulatory risk governance. It should include clear procedures to facilitate risk acceptance by reduction of the uncertainties propagated through the risk assessment and decision-making processes. To establish such a system, it is essential to engage the key stakeholders representing the nanotechnology industries, regulatory entities, insurance companies and the public so that it is eventually tailored to their specific needs.

\section{Radical Adaptation: Making the Tool Useful for Other Stakeholders}

The proposed open access decision support model should support international decision-making on governance of nanomaterials. This means the tool should be useful to policy-makers and a wider stakeholder community rather than just industrial users. Some suggested features of the business ethics tool could be relevant to this more heterogeneous user community. These include the taxonomy of regulatory systems, which may be useful to increase mutual understanding in international dialogue among regulators. The regulatory geography and a warning function for non-tariff trade barriers could also offer useful information in such international dialogue. Thus, both have a much broader remit than nanomaterials or emerging technologies. While policymakers do not use tools, ${ }^{5}$ they may consult experts who could use them. A current practice is the sustainability impact assessment in the preparation of international trade agreements, discussed in the section 'Embedding an Open Access Decision Support System in the International Governance Framework'. This is selected because the international risk governance context for nanomaterials and emerging technologies encompasses negotiations affecting international trade. For example, the OECD Council Decision on Mutual Acceptance of (risk assessment) Data aims to reduce the costs of safety testing in international trade in chemicals.

\footnotetext{
${ }^{5}$ This was confirmed by several stakeholders participating in the questionnaire and workshops held during the SUN project.
}

\section{Constructing an International Governance Framework for Nanomaterials}

A participant in the workshop in Edinburgh mentioned the FramingNano project, funded by the EU in 20082010. This project aimed to "support the establishment of a multi-stakeholders dialogue on NS\&T regulation and governance among the scientific, institutional, industrial communities, the broad public to articulate consensus and absence of consensus between the various stakeholders, sustain a European debate between them, and foster the development of a shared frame of knowledge, objectives, actions to define constructive and practicable regulatory solutions toward a responsible development of NS\&T", 6 One of the main outcomes was the Nanotechnology Governance Continuum, consisting of six stages:

- Defining an assessment methodology

- Collecting data in an observatory

- Interpreting the data in an advisory body

- Evaluation of the advice

- Decision-making

- Feedback to improve the assessment methodology

The participants in the project proposed giving representatives of stakeholders a role in "Identification of Relevant Priorities, Values \& Criteria to Assess Nanotechnology-Induced Change". The so-defined "Common Assessment Methodology" would be provided to a multidisciplinary group of experts monitoring the "State of the Art knowledge on NanotechnologyInduced Change" in an observatory. Its observations would be used to develop advice for decision-making. All these stages would be tasked to a "deliberative panel" offering advice, visions and actions to a separate decision-making body, responsible for evaluation of the proposals and decision-making. The participants proposed adopting "the proposed Governance Platform ... at international level to facilitate cross-border trade and to assure that a responsible development of nanotechnologies takes place worldwide. [It could] be hosted by an existing European or United Nations structure, or an informal intergovernmental organisation" [19].

At the time the proposal was made, the EU also funded the ObservatoryNano project, which served as a blue-print for the observatory at the core of

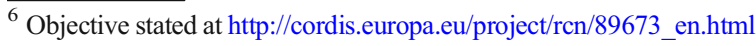


the FramingNano governance continuum. ${ }^{7}$ This ObservatoryNano ended in 2012. In 2016, the EC announced a new EU-Observatory for Nanomaterials, to be hosted by the European Chemicals Agency ECHA. ${ }^{8}$ Such discontinuous progress is inherent in the experimental approach concerning governance of nanotechnology and other emerging technologies. The EC and national governments all over the world have invested in projects investigating different approaches to dialogue and engagement, and risk governance, without reserving funds to ensure data curation of results from finished projects. Many results and insights generated in the past have been forgotten, resulting in duplications of effort and slow progress in decision-making on risk governance of nanomaterials.

Concurrently with the FramingNano project, an international group of authors led by Sheila Jasanoff proposed a 'bioconstitution' governing progress in modern biotechnology [20]. The similar role played by the four DNA 'letters' A, C, G and T in writing the genetic code of human beings and other living organisms, to the letters in the alphabet in writing legal texts, inspired her to coin the term 'bioconstitutionalism'. It also serves to alert to current phenomena caused by the crossing of conceptual lines inherent in legal foundations. It should furthermore illuminate multiple facets of this trend, including rethinking of rights, duties, entitlements and needs of living entities in relation to laws and the State. Bioconstitutionalism is 'a dispersed and active process of reordering and reconstituting knowledge and society'. Case studies discussed in the volume highlight the underlying conflicts in this process. These cases inspired her to propose more democratic participation in development of new regulations for life sciences: "Biopower must be more democratically aligned with the expectations people legitimately cherish about their bodies and selves" [20]. A participant in the workshop in Edinburgh proposed adapting such an international bioconstitution to a nanoconstitution. This could serve as framework for more specific regulations governing different kinds of nanotechnologies, specific applications and stages of the value chain from manufacturing to waste processing.

Both the FramingNano Governance Continuum and the nanoconstitution address the current governance

\footnotetext{
${ }^{7} \mathrm{http} / / /$ cordis.europa.eu/project/rcn/87963_en.html

${ }^{8} \mathrm{http}: / /$ ec.europa.eu/growth/tools-databases/newsroom/cf/itemdetail. cfm?item id $=9023 \&$ lang $=$ en\&tpa id $=0$
}

issues for nanotechnologies including nanomaterials from a policy perspective. However, as Malsch et al. [18] have argued, the current international policy making circuit, where regulation and risk governance focusing specifically on nanomaterials are discussed, is rather fragmented. In addition, issues related to other nanotechnologies, such as privacy and security issues of nanoelectronics, and biomedical ethical issues related to nanomedicine, are discussed in other forums.

Around 2010, the discussion on governance of nanotechnologies was more integrated than today, including risk governance of nanomaterials and potential risks and benefits of other nanotechnologies in the same projects (ObservatoryNano and FramingNano are examples of this). This integration was intentional, inspired by the EU Action Plan for Nanosciences and Nanotechnologies (2005-2009), ${ }^{9}$ which has not been reinforced by a new EU-level policy initiative targeting nanotechnology since then.

Currently, risk governance of nanomaterials is mostly targeted by other projects than those investigating potential benefits and risks of other nanotechnologies, and those fostering public and stakeholder dialogue about applications of nanotechnology. For example, EUfunded projects targeting risks of nanomaterials are coordinated by the European Nano Safety Cluster. ${ }^{10}$ In parallel, the EU continues to fund other projects investigating public perceptions of nanotechnology, and stimulating dialogue on Responsible Research and Innovation in Nanotechnology, but there is no institutional platform where findings of both types of projects are brought together and discussed.

\section{Embedding an Open Access Decision Support System in the International Governance Framework}

Another trend which has emerged since 2010 is the interest in decision support tools for risk governance of nanomaterials. As this option was not considered by the inventors of the FramingNano Governance Continuum or those of the term bioconstitution, it is not obvious where such a tool could fit, who should use it, and what would be the requirements for tool design. Another suggestion by a participant at the workshop in

\footnotetext{
$\overline{9}$ http://ec.europa.eu/research/industrial_technologies/the-policy_en. html

${ }^{10}$ www.nanosafetycluster.eu
} 
Edinburgh may shed some light on how a DSS could be embedded in a risk governance framework.

Since 1999, the EU Commissioner for Trade engages in a mandatory sustainable impact assessment (SIA) during negotiations on international trade agreements. This framework is developed to assess possible impacts of the agreements on selected economic, social, environmental and human rights criteria [21]. An independent consultant is hired to carry out an evidence-based SIA study, incorporating as much as possible quantitative data. This study should be embedded in stakeholder engagement, in a similar vein to the abovementioned FramingNano Governance Continuum. The European Commission does not prescribe the use of specific methods for collecting the data, but imposes a common methodological framework. This includes a causal chain analysis and comparison between the scenario where the trade agreement is adopted, and a baseline scenario without it. The impacts of both scenarios on economic, social, human rights and environmental aspects must be assessed. Facts about past and present developments must be extrapolated towards an 'appropriate time horizon'. The consultants must make systematic use of indicators, offering measurable and comprehensible information. These indicators can be quantitative, such as increase of gross domestic products (GDP), or semiquantitative or qualitative, such as health and safety effects.

To explore the relevance of this Trade SIA for international risk governance of nanomaterials, we need an example of a multilateral agreement focusing on a specific technology or type of product. The SIA in support of the 'Green Goods Initiative' qualifies as such. ${ }^{11}$ This is a trade agreement involving the EU and several other countries in reducing trade barriers for environmental products (and possibly also services). The consultants used a combination of economic (partial equilibrium analysis) and environmental $\left(\mathrm{CO}_{2}\right)$ models, desk research and case studies, to compile the SIA [22].

The modular design of the SUNDS DSS makes it a flexible tool that can be adapted to the requirements of a specific Sustainability Impact Assessment study. As it is, it already incorporates risk control and socioeconomic assessment modules. The latter cover the three traditional pillars of sustainability: environmental (RA and LCA), economic and social aspects. To accommodate the EC SIA specifications, an additional module

\footnotetext{
$\overline{11}$ The SIA was conducted between September 2014 and April 2016.
}

covering human rights should be added, provided it is possible to identify appropriate quantitative indicators that can be fed into a decision tree format. As there are many international treaties, declarations and recommendations covering a wide variety of human rights, it would also be necessary to focus on those rights that are related to nanomaterials or emerging technologies in general. Some of those texts are listed in Table 1 below. They can be classified as sustainable development, chemicals safety and responsible science, technology and innovation.

\section{Discussing Computer-aided International Dialogue on Regulating Nanomaterials}

In the section "Exploring Stakeholder Suggestions", we have elaborated on the suggestions made by participants in the workshop in Edinburgh. Below, we will develop our own future scenario combining an adapted DSS with an international governance framework. Using the SUNDS DSS in Sustainability Impact Assessment for an international agreement is not straightforward, since now the 'object' causing the assessed impacts is not a material or product, but a proposed legal text, a 'nanoconstitution'. As it is, the SUNDS DSS could be used to generate (semi) quantitative data for case studies highlighting the impact of an international 'nanoconstitution' on the viability of a specific nanomaterial or nanoproduct. In the current system, users can develop a scenario assessing the risks and socio-economic impacts of the manufacturing, use, and waste processing of a nanoproduct, and compare this to a similar scenario adding RMM, where needed. Likewise, the impacts of the same product could be compared in the presence or absence of the proposed 'nanoconstitution'. The usefulness of the tool could be improved by adding an additional module on human rights, as well as the abovementioned business ethics tool, to the existing socio-economic assessment modules, including (in addition to risk assessment), life cycle impact assessment, economic assessment and social impact assessment.

Development of a DSS for sustainability impact assessment of a 'nanoconstitution' calls for a complete redesign of the current SUNDS, taking the legal requirements as inputs rather than the properties of a nanomaterial. The modular design offers a good starting point. As in the SIA for the 'Green Goods Initiative', 
Table 1 Some international treaties and declarations relevant to emerging technologies

\begin{tabular}{|c|c|c|}
\hline Sustainable development & Chemicals safety & $\begin{array}{l}\text { Responsible science, technology and } \\
\text { innovation }\end{array}$ \\
\hline $\begin{array}{l}\text { - UN Conference on Human } \\
\text { Environment (1972) }\end{array}$ & $\begin{array}{l}\text { - OECD: Council Decision on Mutual Acceptance of } \\
\text { Data (MAD) (1981) }\end{array}$ & $\begin{array}{l}\text { - International Covenant on Economic, } \\
\text { Social \& Cultural Rights (1966): freedom } \\
\text { of scientific progress }\end{array}$ \\
\hline $\begin{array}{l}\text { - Rio Declaration on Environment \& } \\
\text { Development (1992) }\end{array}$ & $\begin{array}{l}\text { - UNECE Globally Harmonised System of } \\
\text { Classification and Harmonisation of Chemicals } \\
\text { (GHS) (2002) }\end{array}$ & $\begin{array}{l}\text { - UNESCO Recommendation on the Status } \\
\text { of Scientific Researchers (1974) [currently } \\
\text { under revision] }\end{array}$ \\
\hline $\begin{array}{l}\text { - Convention on Biological } \\
\text { Diversity (1993) }\end{array}$ & $\begin{array}{l}\text { - ICCM: Strategic Approach to International } \\
\text { Chemicals Management (SAICM) (2006) }\end{array}$ & $\begin{array}{l}\text { - UNESCO Universal Declaration on the } \\
\text { Human Genome and Human Rights } \\
\text { (1997) }\end{array}$ \\
\hline $\begin{array}{l}\text { - World Summit on Sustainable } \\
\text { Development (2002) }\end{array}$ & $\begin{array}{l}\text { - OECD Council Recommendation on Nanomaterials } \\
\text { (September 2013) }\end{array}$ & $\begin{array}{l}\text { - UNESCO Universal Declaration on } \\
\text { Bioethics and Human Rights (2005) }\end{array}$ \\
\hline $\begin{array}{l}\text { - Aarhus Convention on Access and } \\
\text { Participation in Environmental } \\
\text { Matters (1998) }\end{array}$ & $\begin{array}{l}\text { - ILO: Global Action for Prevention on Occupational } \\
\text { Safety and Health (OSH GAP) }\end{array}$ & $\begin{array}{l}\text { - Council of Europe Convention for the } \\
\text { protection of human rights and } \\
\text { fundamental freedoms, }\end{array}$ \\
\hline $\begin{array}{l}\text { - RIO + } 20 \text { (2012): Future we } \\
\text { want-outcome document-UN } \\
\text { General Assembly }\end{array}$ & $\begin{array}{l}\text { - FAO/WHO: risk assessment/management of } \\
\text { nanotechnologies and nanomaterials in food and } \\
\text { agriculture sectors }(2013)^{12}\end{array}$ & $\begin{array}{l}\text { - Council of Europe: convention on human } \\
\text { rights and biomedicine (Bioethics } \\
\text { Convention (Oviedo)) }\end{array}$ \\
\hline $\begin{array}{l}\text { - UN Sustainable Development } \\
\text { Goals }(2015-2030)\end{array}$ & $\begin{array}{l}\text { - WHO: Inter-Organisation Programme for the Sound } \\
\text { Management of Chemicals }{ }^{13} \\
\text { - UNITAR: national capacity building risk governance } \\
\text { for nanomaterials }{ }^{14}\end{array}$ & • EU Charter of fundamental rights (2000) \\
\hline
\end{tabular}

including the partial equilibrium analysis could be envisaged in the economic assessment module, and a model estimating $\mathrm{CO}_{2}$ equivalent emissions is included in the life cycle assessment module, as the midpoint called climate change. Other existing models that could be incorporated must be identified in consultation with the prospective users of the tool.

\section{Data and Values}

The original outline for the SUNDS decision support tool included the option of inserting personalised weights reflecting the user's assessment of the relative importance of the criteria addressed by the different modules (e.g. valuing the output of economic assessment higher than the output of social impact assessment). After consultation with experts and stakeholders, this weighting option has not been implemented in the current tool design targeting industrial users. In the context of international dialogue on regulation and risk governance of nanomaterials, such weighting may be more relevant. The reason is that regulatory decisionmaking should take into account scientific evidence, but also political positions and value conflicts in society.
The weighting could serve as an indicator for such value conflicts.

The discussions in our project with potential users and stakeholders about a potential open access DSS for international dialogue on regulation and risk governance of nanomaterials have considered the option of inserting value-based weights as well as scientific data. To avoid mixing of data and values, such an open access tool would need an explicit feature assessing data quality based on transparent quality assessment criteria. This could be through peer review if automatic quality control turns out to be too complex. In this case, peer review means that each input of a data set would have to be checked by an independent other expert before being accepted. However, automatic quality control can be achieved if the DSS is linked to the data curation system that was introduced by the eNanoMapper project ${ }^{12}$ and is currently being upgraded in the NanoReg $2^{13}$ and caLIBRAte ${ }^{14}$ projects.

The open access tool would need two entry points, one for an interdisciplinary group of qualified experts

\footnotetext{
12 http://www.enanomapper.net/

13 http://www.nanoreg2.eu/

${ }^{14} \mathrm{http}: / /$ www.nanocalibrate.eu/home
} 
inserting data, including industrial experts incorporating corporate data. The other entry point should be for stakeholders including industry, civil society, regulators and others inserting their personal weights for each of the criteria addressed by the MCDA performed by the system. ${ }^{15}$ A study comparing mental models of potential regulatory, industrial and insurance sector users of the SUNDS DSS, resulted in some evidence that different stakeholder groups assign different weights to risk assessment, life cycle assessment, economic assessment and social impact assessment tools [17].

The output of the tool should visualise how the individual stakeholder's weights compare to the average weighting of his or her stakeholder group, and to the average weighting of other stakeholder groups. In addition, it should allow consideration of the degree of group consensus by displaying weights' variance among stakeholders in the group, and by tracking changes in weighting per stakeholder group over time. This track changes could then become an indicator for monitoring value conflicts between stakeholder groups. The input of data with associated uncertainty margin by recognised experts, subject to peer review, may contribute to more transparent formation of a new multidisciplinary epistemic community in charge of generating and inserting the data. Ultimately, this new epistemic community should support evidence-based international regulation. The input of weights by all interested stakeholders and the resulting indicators for monitoring value conflicts between stakeholder groups should be useful for all stakeholder representatives participating in dialogue on international regulation. This should support more democratic international regulation (see Fig. 1).

\section{Grounding Neutrality and Relevance of the Tool}

A commonly recognised problem in international governance discussions is the formation of epistemic communities of experts, mixing scientific facts and moralpolitical values [23]. This is even more problematic when the scientific evidence needed for decisions on new regulation depends to a significant extent on data contributed by industrial experts, or other stakeholders having an interest in the outcome of the regulatory

\footnotetext{
$\overline{15}$ Deciding who is qualified to be an expert, and on which aspect, is not straightforward, given the current discussion on the formation and roles of epistemic communities in evidence based decision making $[18,23,24]$.
}

process. The proposed new DSS addresses this mixing of expertise and interests through quality control of factual data and through separating input channels for data and values, as depicted in Fig. 1.

The earlier-mentioned problem that policy-makers do not use tools in decision-making on regulation and governance, implies that the relevance of even the most sophisticated and useful tools is limited in practice. We propose to improve the relevance of the described DSS by integrating it in a risk governance framework, as explained below.

\section{Connecting the Tool and the Governance Continuum}

Just offering a tool to the existing participants in the international dialogue on risk governance of nanomaterials is unlikely to make much difference. Most probably, it will not be used, because the regulators and stakeholders currently do not use tools. Working with the tool should be an integral element of a risk governance continuum, as proposed in the FramingNano project. The design of the tool should first be discussed by the stakeholders engaged in "Identification of Relevant Priorities, Values \& Criteria to Assess NanotechnologyInduced Change". In the case of the SUNDS system, this early user engagement has helped target the tool to needs of companies preparing dossiers demonstrating compliance with existing legislation ([9]). It has also generated suggestions for version 1.0 of an open access DSS for international dialogue on regulation of nanomaterials (c.f. [18]). This first version could be incorporated in the definition of a common assessment methodology. This should clearly distinguish which criteria and values are (semi) quantitative and can be incorporated in a decision support tool, and which require other, qualitative methods. The common assessment methodology should then be provided to a multidisciplinary group of experts, using it to monitor the "State of the Art knowledge on NanotechnologyInduced Change" in an observatory. The output of this analysis must be discussed with stakeholders and translated into an advice, which forms the basis of decisionmaking after evaluation by the stakeholders, resulting in feedback which can be the starting point for reiterating the cycle. Embedding the tool in this governance continuum highlights the potential added value as well as its limitations in the light of evidence-based and democratic 


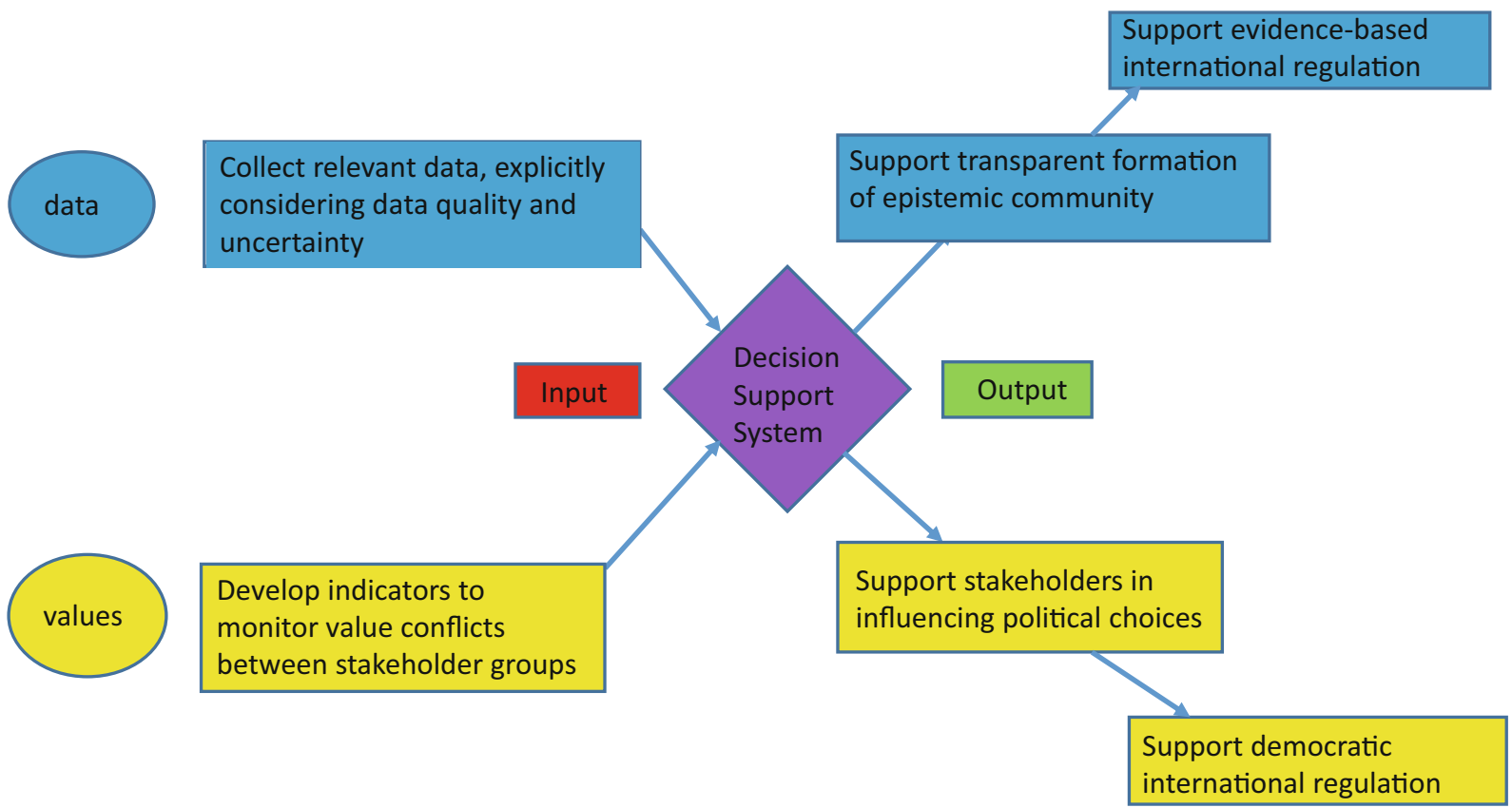

Fig. 1 Distinguishing input of data and values, and their respective roles in decision-making on regulation of nanomaterials and other emerging technologies

decision-making. Figure 2 depicts how the tool could be embedded in the governance cycle.

\section{Embedding Tool Enabled Risk Governance in Current International Decision-Making}

International dialogue about regulation and risk governance of nanomaterials is currently distributed over several interconnected platforms (see Fig. 3). Two locations seem most suitable for embedding a decision support tool. The most democratic and most central location would be the Strategic Approach to International Chemicals Management (SAICM), because this forum has well-established procedures for effective wide stakeholder engagement. The downside is that it has no legislative authority and can only make recommendations. It depends on the goodwill of each state whether the recommendations will be translated into national legislation. The impacts of any recommendation originating from the SAICM will therefore be only indirect and difficult to assess.

The OECD Council does have the authority to adopt international regulations, which are binding to their member states and to other countries signing up to them. The downsides are that not all countries where nanomaterials are manufactured or used are OECD members or observers, and that in practice, stakeholder engagement remains mainly limited to industry (represented by BIAC) ${ }^{16}$ and (in the case of nanomaterials to a lesser extent) trade unions (represented by TUAC). ${ }^{17}$ The impact of binding OECD Council Decisions would be easier to assess as part of an SIA, while less countries would be affected than by SAICM recommendations.

\section{Contrasting our Proposal with Alternative Ways of Citizen Involvement}

For comparison, Kica and Wessels [26] discussed the contributions to international dialogue on risk governance of nanomaterials of five informal 'transnational arrangements' active in the period 2005-2012. These include the Working Party on Manufactured Nanomaterials (WPMN) at the OECD, the Intergovernmental Forum on Chemical Safety (IFCS, hosted by the World Health Organisation, predecessor of the

\footnotetext{
$\overline{16}$ The Business and Industry Advisory Committee to the OECD, http://biac.org/

${ }^{17}$ The Trade Union Advisory Committee to the OECD, http://www. tuac.org/en/public/index.phtml
} 
Fig. 2 Governance cycle for emerging technologies incorporating decision support system. The red box indicated design of the system, blue boxes indicate data handling, yellow boxes indicate weighting, green boxes indicate stakeholder and citizen engagement, and the purple indicates political decision-making

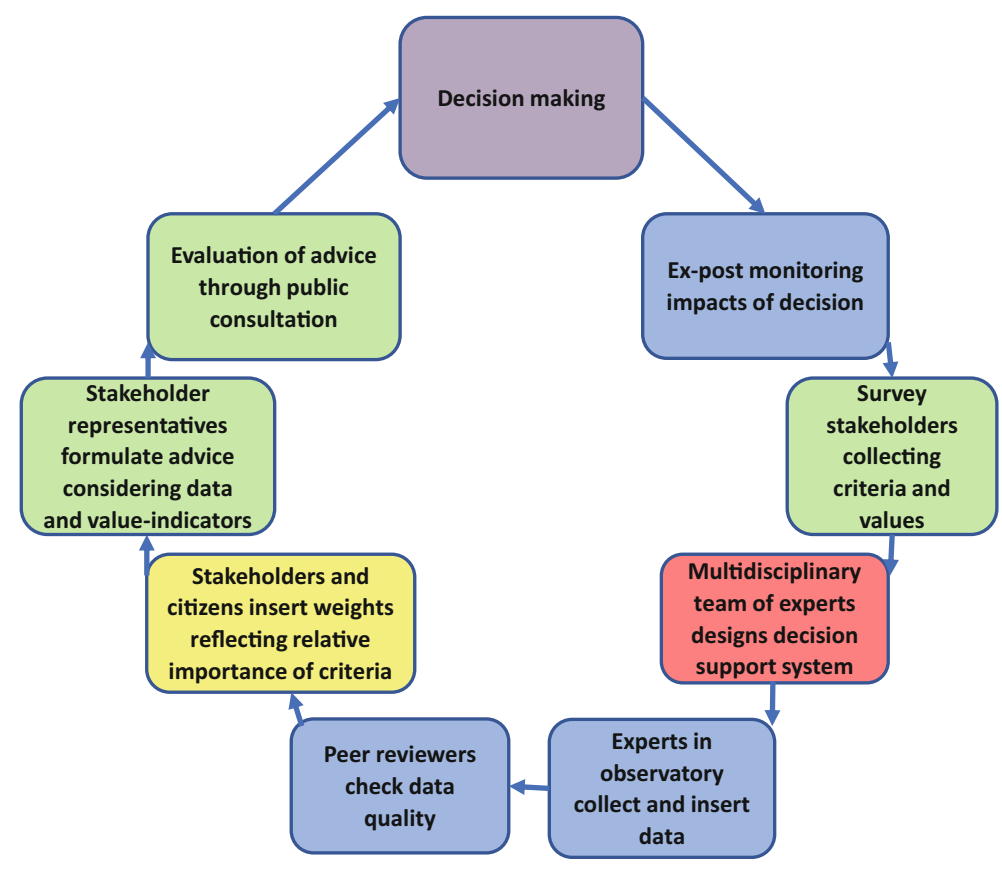

SAICM), the ISO Technical Committee TC 229 (nanotechnologies), the International Risk Governance Council (IRGC, Switzerland) and the International Council on Nanotechnology (ICON, hosted by Rice University, USA). They consider the likely impact of the WPMN and ISO TC 229 to be the largest. While acknowledging

UN Inter-Organisation Programme for the Sound Management of Chemicals (IOMC);

Strategic Approach to International Chemicals Management (SAICM) - Emerging Policy Issues

This policy framework was adopted by the International Conference of Chemicals Management

(ICCM), targeting the World Summit on Sustainable Development (WSSD, 2002) goal:

By 2020, chemicals should be produced and used in ways that lead to the minimization of significant adverse effects on human health and the environment.

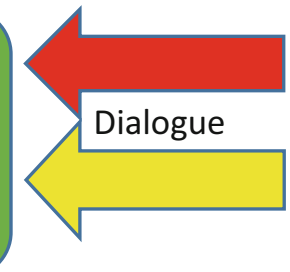

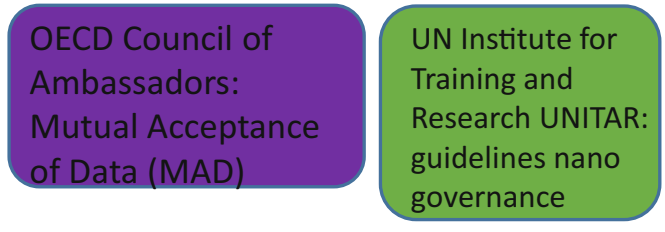
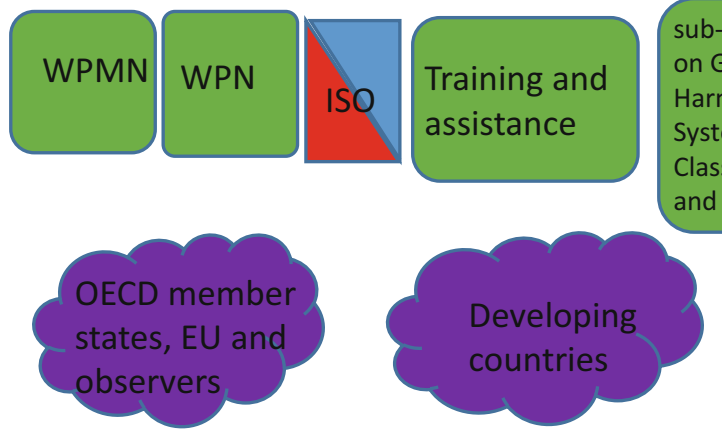

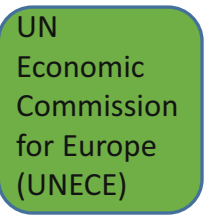

sub-committee on Globally Harmonized System (GHS) of Classification and Labelling

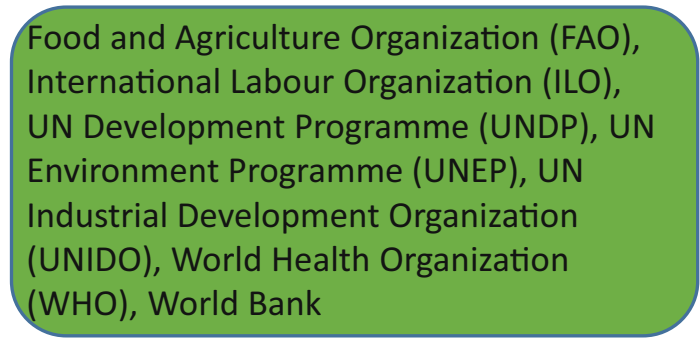

International organisations

Legislative authorities

\section{Private companies}

\section{Research organisations}

\section{Civil Society Organisations}

Fig. 3 The main platforms where international dialogue on regulation and risk governance of nanomaterials takes place (c.f. [24]) 
efforts of the organisers of all five arrangements to organise wider stakeholder engagement, they signal "many questions over the clear lines of accountability, stakeholder representation, roots of decision making and reasons for social acceptability" [26].

Our proposed decision support tool embedded in a risk governance framework, specifying clear roles for stakeholders, experts and decision-making could contribute to solving some of these issues. Accountability of the decision-making process can be improved by the output of the tool, clearly distinguishing the facts and stakeholder values considered, in one dashboard accessible to anyone through the internet. Stakeholder representation can be improved through an online tool where anyone can insert their value preferences, which is less time and resources consuming than participation in face-to-face meetings. This would lower the threshold for participation. Roots of decision-making can also be made more transparent by bringing together information on data and values in one dashboard. Reasons for social acceptability can be articulated through the participation of stakeholders in determining the criteria, and in evaluating the output of the tool in the governance cycle depicted in Fig. 2.

\section{Conclusion: Proposing a Scenario for Computer-aided International Governance of Emerging Technologies}

The scenario developed in this article aims to propose a new way of international decision-making on regulating emerging technologies, one that should both be more democratic and more evidence-based than existing ones. This new approach recombines good practices from earlier, mainly EU-based, initiatives, identified through constant comparison.

Decision-makers wishing to use this method of computer-aided international governance of emerging technologies, should a priori identify the most appropriate international platform where binding agreements regulating the emerging technologies in question can be adopted, with the widest geographical coverage. The fate of earlier initiatives, including FramingNano, ObservatoryNano and the proposal for a more democratic bioconstitution, has demonstrated that good ideas are not viable if they are not implemented by policy-makers in the right places. Sufficient resources should be made available for completing the governance cycle at least once. The cycle should start by surveying stakeholders' views on the appropriate criteria and values that should form the basis of decision-making. This should in any case include environmental, economic, social and human rights aspects of sustainability. Then, an interdisciplinary group of experts will design a DSS plus any qualitative research methods required for collecting the data and information on values. Subsequently, experts from all the relevant areas of science will insert the data, which should only be accepted after peer review by an independent expert from the same field. In parallel or after this, all stakeholders and citizens from the affected countries should be invited to insert weights, reflecting the relative importance they assign to each of the criteria (e.g. risks, environmental impacts, social issues, economy or human rights). This will generate indicators for comparison of potential value conflicts between groups of stakeholders or between citizens from different countries. Then, a balanced group of representatives of stakeholders should consider the data and information on values, and prepare an advice for policy-making. Subsequently, this advice is to be evaluated through a public consultation inviting all stakeholders and citizens of the affected countries. The stakeholder representatives should update their advice, taking on board all the comments, and submit it to the political decision-makers, who can then decide on how to regulate the emerging technologies. After adoption of the legislation, its implementation should be monitored and when appropriate, the governance cycle can start anew (see Fig. 2).

The stakeholders participating in the survey, interviews or workshops, held during the SUN project, mentioned several objections against an open access decision support tool for international dialogue on regulation on emerging technologies. A major issue is confidentiality of business information. This is problematic in the case of regulating nanomaterials, because regulators need risk assessment data from tests performed by companies to reduce uncertainty of the potential risks, and to generate information on which materials are being used in products on the market. Relying only on academic researchers will not fulfil the need for data enabling timely decision-making on regulation. Companies can be legally compelled to deliver data to authorities, but this tends to be subject to confidentiality, which reduces the transparency of decision-making and limits the effectiveness of peer review. Some stakeholders in our project also considered openness to be in the interest of companies, since 
this may help improve trust among consumers and downstream users of nanomaterials. Another way to convince companies to be more open is through 'naming and shaming' by civil society organisations. For example, an international consortium of investors interested in sustainable development recently launched a new “Corporate Human Rights Benchmark", ranking 98 multinational companies on their corporate policies for respecting human rights. ${ }^{18}$ The initiators assess public information offered by each company on 100 human rights indicators they developed after consultation with the companies and other stakeholders.

Another issue is the risk of misinterpretation and bias inherent in public use of an open access DSS. This is addressed by engaging stakeholders in the selection of criteria and values for designing the DSS and methodology, and by incorporating peer review and public consultations in the governance cycle. This helps construct a common understanding and articulation of underlying value-differences and conflicts of interest.

Some would consider this scenario unrealistic, and argue that it makes more sense to focus on developing the SUNDS tool further for industrial applications in the context of compliance with formal or informal regulations. Indeed, this seems to be the best way forward for the SUNDS tool as it is now, which has been tailor-made for such use. However, the discussion of the sustainable impact assessment methodology developed by the EU for negotiations on international agreements shows that there is increasing interest in using tools in the policymaking context at global level. The primary users are expected to be consultants rather than policy-makers. In addition, the design of the SUNDS tool has evolved during the project, influenced by discussions with potential users. It is possible to retrace these steps and make different design choices, ending up with a tool which is more adapted to the needs of stakeholders participating in dialogue on governance of nano and other emerging technologies.

The scenario of computer-aided international governance of emerging technologies, proposed in this paper, can now be tested in a real-world environment. Such a case study should preferably be different from the international dialogue on risk governance of nanomaterials, to check whether the scenario has more universal validity for emerging technologies in general.

\footnotetext{
$\overline{18 \text { https://www.corporatebenchmark.org/ }}$
}

Acknowledgements We gratefully acknowledge the contributions of the participants during the stakeholder workshop analysed here, and constructive comments by three anonymous reviewers.

\section{Compliance with Ethical Standards}

Conflicts of Interest The research leading to these results has received funding from the European Union Seventh Framework Programme [FP7/2007-2013] under EC-GA No. 604305 'SUN'. This publication reflects the views only of the authors, and the European Commission cannot be held responsible for any use, which may be made of the information contained therein.

Human Participants and/or Animals, and Informed Consent The research has not involved animals. The participants in the workshop have been asked to give their informed consent to publication of results in anonymised form, and have been given the chance to comment on the draft summary report in the annex before publication.

\section{Annex 1: SUN Stakeholder Workshop 3 - Summary Report}

Location and date: Heriot Watt University, Edinburgh, 6 October 2016, 9.00-13.30.

\section{Summary}

The aim of the workshop was to generate ideas for potential future uses of the SUNDS DSS. The first version of this tool has been developed in the SUN project, and it will be further developed in the subsequent project CALIBRATE. The following issues were discussed:

- There is a risk of misinterpretation and bias in case of public use of output. The SUNDS tool consists of a screening level self-assessment tool and a more data-rich tier 2. The quality of the output depends on the quality of the data, which the company or other user inserts. The output cannot be taken at face value by non-experts such as SME owners or politicians, but needs expert interpretation. This introduces a risk that the output of the tool could be biased and misinterpreted by decision-makers.

- The lack of good quality data and common definitions are more pressing needs than the lack of decision support tools. Several initiatives are underway to develop ontologies, uniform descriptions, 
nomenclature and definitions in EU funded projects, at the OECD, ISO and other platforms.

- SUNDS may support in-company teams of experts compiling a REACH dossier. The current design of the tool can be installed by companies in their intranet. Different users can be created who can insert risk assessment experimental results and other data. Similarly, use in an industrial consortium collaborating in data generation may also be possible. Confidentiality and proprietary data issues are barriers preventing more open access applications.

- Primary insurance companies might be interested to use such a tool, but only to facilitate data collection, not as an expert system. Reinsurance companies would not be interested, as their market is based on differences in risk appetite. Standardisation would eliminate this market. Companies applying for insurance policies could perhaps be offered a discount if they use the tool in generating their risk assessment.

- In CALIBRATE, a viable business model for exploitation of the tool should be developed, through embedding in appropriate partnerships. On a practical level, services and consultancy fees could be charged to make the tool self-sustainable. On a more strategic level, the tool should be embedded in the right partnerships. Cooperation with ECHA is needed to make the tool useful for SMEs interested in compliance with REACH. For policy-makers, a tool could be useful that supports sustainability impact assessments for international trade agreements.

- The use of SUNDS could create uncertain judgments in court. For some judges, evidence that a company had used the tool and toggled its risk appetite could be taken as an indicator that the company was aware of the risk. For others, it might be considered an indicator that the company was taking a precautionary approach.

- How could the design of the SUNDS tool be adapted to accommodate differences in regulatory systems?

- An additional module could be envisaged that includes a taxonomy of regulatory regimes. This could be useful for supporting joint regulatory risk assessment, for example

- high and low cost legal systems,

- open and closed legal systems and

- strict and low liability system.
- A common 'nanoconstitution' could be envisaged, offering a framework for more specific rules that can be applied to specific nanotechnologies. This could go beyond traditional risk assessment. Such a framework has been developed in the EU funded FramingNano project.

- A business ethics tool could be useful. It could incorporate a function warning if you are breaking current regulations in any country. Regulatory geography along the supply chain of a product could also be included to warn for non-tariff trade barriers.

- Could the tool support traceability-by-design of nanoproducts? This might be more easy for end products such as pharmaceuticals and food, than for nanomaterials and chemicals.

- Viability of a wiki-tool supporting public dialogue on nanorisk governance

- Confidentiality of data generated by companies is a key bottleneck preventing an open access version of the decision support tool for nano. This data is needed for risk governance and regulation, but companies have valid reasons not to make this data public. However, there are ways to disclose at least some data that are already used.

- However, an open wiki-like tool could support trustbuilding in nanotechnology among citizens. This could be primarily in the interest of industry. Current barriers preventing participation of CSOs in risk governance are primarily economic, not legal. Differences in business cultures also influence their willingness to take responsibility for risk governance.

- Politicians will not use tools, but they may listen to experts who could use the tools.

- Participants with different backgrounds revealed different evaluations of risks and benefits and different tolerance to uncertainty.

Participants list

\begin{tabular}{lc}
\hline Dr Francoise Roure & $\begin{array}{c}\text { Ministry Economy \& Finance, } \\
\text { France }\end{array}$ \\
Dr Igor Linkov & US Army Corps of Engineers, USA \\
Dr Florian & University of Limerick, Ireland and \\
David-Spickermann & SCOR Reinsurance, Germany \\
Dr David Carlander & Nanotech Industry Association, \\
& Belgium \\
Prof Dr Martin Mullins & University of Limerick, Ireland \\
Dr Elena Semenzin & Ca'Foscari University Venice, Italy
\end{tabular}


Participants list

Dr Alex Zabeo

Ms Stella Stoycheva

Dr Ineke Malsch
Ca'Foscari University Venice, Italy

Ca'Foscari University Venice, Italy

Malsch TechnoValuation,

The Netherlands

\section{References}

1. McLeod R, Schell GP (2007) Management information systems, 10th edn. Prentice Hall, Upper Saddle River

2. Miller K, Mansingh G (2017) OptiPres: a distributed mobile agent decision support system for optimal patient drug prescription. Inf Syst Front 19(1):129-148

3. Cebi S, Akyuz E, Sahin Y (2017) Developing web based decision support system for evaluation occupational risks at shipyards. Brodogradnja 68(1):17-30

4. Bohanec M, Boshkoska BM, Prins TW, Kok EJ (2017) SIGMO: a decision support system for identification of genetically modified food or feed products. Food Control 71:168-177

5. Gibson FL, Rogers AA, Smith AD, Roberts A, Possingham H, McCarthy M, Pannell DJ (2017) Factors influencing the use of decision support tools in the development and design of conservation policy. Environ Sci Pol 70:1-8

6. Kumar A, Sah B, Singh AR, Deng Y, He X, Kumar P, Bansal RC (2017) A review of multi criteria decision making (MCDM) towards sustainable renewable energy development. Renew Sust Energ Rev 69:596-609

7. Marinakis V, Doukas H, Xidonas P, Zopounidis C (2017) Multicriteria decision support in local energy planning: an evaluation of alternative scenarios for the sustainable energy action plan. Omega 69:1-16

8. van Harmelen T, Zondervan-van den Beuken EK, Brouwer DH, Kuijpers E, Fransman W, Buist HB, Ligthart TN, Hincapie I, Hischier R, Linkov I, Nowack B, Studer J, Hilty L, Som C (2016) LICARA nanoSCAN - a tool for the self-assessment of benefits and risks of nanoproducts. Environ Int 91:150-160

9. Subramanian V, Semenzin E, Hristozov D, Zabeo A, Malsch I, McAlea E, Murphy F, Mullins M, van Harmelen T, Ligthart T, Linkov I, Marcomini A (2016) Sustainable nanotechnology decision support system: bridging risk management, sustainable innovation and risk governance. J Nanopart Res 18:89. https://doi.org/10.1007/s11051-0163375-4

10. Som C, Zondervan-van den Beuken E, Van Harmelen T, Güttinger J, Bodmer M, Brouwer D, Buist HE, Carroll R, Coll C, Fransman W, Hartmanis A, Hincapie I, Hischier R, Karachalios T, Kouravelou K, Kuijpers E, Ligthart T, Notter D, Nowack B, Seibold U, Schneider G (2014) LICARA guidelines for the sustainable competitiveness of nanoproducts. Dübendorf, St. Gallen, Zeist

11. TÜV SÜD Industrie Service (2013) Certification Standard CENARIOSTM. Available at http://www.tuevsued.

de/uploads/images/1219824286015340810363 /CENARIOS_Zertifiziergrundlage_e.pdf

12. Widler T, Meili C, Semenzin E, Subramanian V, Zabeo A, Hristozov D, Marcomini A (2016) Organisational risk management of nanomaterials using SUNDS: the contribution of CENARIOS $^{\text {TM }}$. In: Murphy F, McAlea E, Mullins M (eds) Managing risk in nanotechnology. Topics in governance, assurance and transfer. Springer International Publishing Switzerland, pp 2-19-235

13. Subramanian V, Semenzin E, Hristozov D, Zabeo Z, Malsch I, Saling P, van Harmelen T, Ligthart T, Marcomini A (2016) Integrating the social impacts into risk governance of nanotechnology. In: Murphy F, McAlea E, Mullins M (eds) Managing risk in nanotechnology. Topics in governance, assurance and transfer. Springer International Publishing Switzerland, pp 51-70

14. Subramanian V, Semenzin E, Zabeo A, Sailing P, Ligthart T, van Harmelen T, Malsch I, Hristozov D, Marcomini A (2018) Assessing the social impacts of nano-enabled products through the life cycle: the case of nano-enabled antimicrobial paint.. Int J Life Cycle Assess. https://doi. org/10.1007/s11367-017-1324-9

15. Malsch I, Subramanian V, Semenzin E, Hristozov D, Marcomini A (2014) Collective decision making on risk management and sustainable manufacturing of nanomaterials and the role of decision support tools. In Proceedings 5th STS Italia conference a matter of design: making society through science and technology. Milan, http://www.stsitalia.org/?p=1548\&lang=en; pp 12-14

16. Malsch I, Subramanian V, Semenzin E, Hristozov D, Marcomini A (2015) Supporting decision making for sustainable nanotechnology. Environ Syst Dec 35(1):54-75

17. Malsch I, Subramanian V, Semenzin E, Zabeo A, Hristozov D, Mullins M, Murphy F, Linkov I, Marcomini A (2017) Comparing mental models of prospective users of the sustainable nanotechnology decision support system. Environ Syst Dec 37(4):465-483

18. Malsch I, Subramanian V, Semenzin E, Hristozov D, Marcomini A, Mullins M, Hester K, McAlea E, Murphy F, Tofail SAM (2015) Empowering citizens in international governance of nanotechnologies. J Nanopart Res 17:215. https://doi.org/10.1007/s11051-015-3019-0

19. Widmer M, Meili C, Mantovani E, Porcari A (2010) The FramingNano Governance Platform: a new integrated approach to the responsible development of nanotechnologies, http://cordis.europa.eu/project/rcn/89673 en.html

20. Jasanoff S (ed) (2011) Reframing rights. Bioconstitutionalism in the genetic age. MIT Press, Cambridge/MA

21. European Commission (2016) Handbook for trade sustainability impact assessment, 2nd edn. European Commission, Brussels http://ec.europa.eu/trade/policy/policymaking/analysis/sustainability-impactassessments/

22. Development Solutions (2016) Trade sustainability impact assessment on the environmental goods agreement. Final Report. European Commission, Brussels http://www. egatradesia.com/

23. Haas PM (1992) Introduction: epistemic communities and international policy coordination. Int Organ 46(1):1-35

24. Klaessig FG (2014) Developing official practices for nanoEHS data compilation, curation and compliance. In: Coenen C, Dijkstra A, Fautz C, Guivant J, Konrad K, 
Milburn C, van Lente H (eds) Innovation and responsibility: engaging with new and emerging technologies, S.NET 005. IOS Press and AKA, Heidelberg, pp 121-133

25. SAICM (2015) Emerging policy issue update on nanotechnologies and manufactured nanomaterials. International Conference on Chemicals Management, 4th session, Geneva, 28 September-2 October 2015, Item 5 (b) (iii) $\mathrm{d}$ of the provisional agenda, http://www.saicm.org/
26. Kica E, Wessels RA (2017) Transnational arrangements in the governance of emerging technologies: the case of nanotechnologies. In: Bowman D, Stokes E, Rip A (eds) Embedding new technologies into society. A regulatory, ethical and societal perspective. Pan Stanford, Singapore, pp 219-258 